\title{
Resection of meningiomas in a different location (sphenoid wing and tuberculum sellae) through a single craniotomy report of a case and review of the literature
}

\author{
Resección de meningiomas en diferente localización (temporal y sellar) mediante \\ craneotomía única reporte de un caso y revisión de la literatura
}

\author{
José L. Navarro-Olvera ${ }^{1 *}$, Gustavo Parra-Romero", José D. Carrillo-Ruiz ${ }^{1,2,3}$, Gustavo Aguado-Carrillo, \\ and Aldo F. Hernández-Valencia ${ }^{1}$ \\ ${ }^{1}$ Department of Functional Neurosurgery, Stereotactic and Radiosurgery, Hospital General de México; ${ }^{2}$ Department of Research Direction, Hospital \\ General de México; ${ }^{3}$ Department of Health Sciences, Anahuac University North Campus. Mexico City, Mexico
}

\begin{abstract}
Meningiomas are the most frequent extra-axial tumors of the nervous system. Multiple meningiomas are defined as the presence of two or more lesions that appear simultaneously or not, in different intracranial location, without association to neurofibromatosis. Each lesion must be evaluated individually for treatment, which consists in microsurgical resection in most cases. A 59-year-old woman presented with neurological symptoms from different anatomical site. Two extra-axial tumors of different location, at right sphenoid wing and the other in the tuberculum sellae were identified. Microsurgical resection was decided in one-step surgery, using the same craniotomy for both lesions with complete resection.
\end{abstract}

Key words: Meningiomas. Meningiomatosis. Neurofibromatosis. Resection. Single craniotomy.

\section{Resumen}

Los meningiomas son los tumores extraaxiales más frecuentes del sistema nervioso. Los meningiomas múltiples o meningiomatosis (MM) se definen como la presencia de 2 o más lesiones que aparecen simultáneamente o no, en diferente localización intracraneal, sin asociación con neurofibromatosis. Cada lesión debe ser evaluada de manera individual para su tratamiento. Presentamos una paciente con meningiomatosis. La sintomatología era muy variada de localizaciones anatómicas diferentes. En los estudios de imagen, se identificaron tumores extra axiales de diferente localización, una lesión alar y otra del tubérculo sellar. Se decidió la resección microquirúrgica en un solo tiempo, mediante la misma craneotomía.

Palabras clave: Meningiomas. Meningiomatosis. Resección. Craneotomía. Única. Neurofibromatosis.

Date of reception: $01-11-2020$

Date of acceptance: 11-03-2021

DOI: $10.24875 /$ CIRU.20001193

E-mail: luiginavarro97@ hotmail.com

0009-7411/@ 2021 Academia Mexicana de Cirugía. Published by Permanyer. This is an open access article under the terms of the CC BY-NC-ND license (http://creativecommons.org/licenses/by-nc-nd/4.0/).
} 


\section{Introduction}

Meningiomas are intracranial but extra-axial tumors, originating from arachnoid cells, accounting for approximately $35 \%$ of brain tumors in adults. The meningiomas incidence is higher as age increases ${ }^{1}$. Most cases tend to be histologically benign, with an approximate growth rate per year of $0.03-2.62 \mathrm{~cm}^{32}$.

Multiple meningiomas (MM) or meningiomatosis is defined as the presence of two or more lesions that appear simultaneously or not, in a different intracranial location. MM are considered to constitute $1-9 \%$ of meningioma cases and have a slight tendency to be more frequent in women ${ }^{3}$. The appearance mechanism of MM is still unknown. A theory postulates that these tumors arise one independent of the other while another mentions a unique transformation of the same cell clone, with spread through the cerebrospinal fluid ${ }^{4}$.

Ionic radiation is among the risk factors for the formation of MM. The concept of radio-induced tumors was first described by Cahan in 1948, since he observed the appearance of new neoplastic lesions 5 years after radiation, in the absence of other predisposing factors ${ }^{5}$. Radio-induced meningiomas were observed among survivors of the Hiroshima and Nagasaki atomic bomb, given the high ionizing radiation dose during childhood. This finding leads to the consider ionizing radiation as a predisposing factor for MM, which is currently better known and studied ${ }^{6-9}$.

Surgery is undoubtedly the treatment of choice when focal neurological manifestations due compression of specialized regions exists or when the lesion generates drug-resistant epilepsy. Among the current management strategies for meningiomas are microsurgical resection, endoscopic assistance, or radiosurgery for those skull base tumors smaller than 3 $\mathrm{cm}^{310}$. If the different meningiomas have any proximity, they can be resected by a single craniotomy ${ }^{11}$.

\section{Case report}

A 59-year-old woman with the previous history of diabetes and hypertension with regular treatment, without known exposure to radiation presented to our department due to a 2-year evolution with moderate intensity holocranial headache and progressive bilateral decrease in the visual field, predominantly in the right side. She also manifested four episodes of behavioral arrest, fear sensation, and search automatism lasting approximately $5 \mathrm{~min}$ with subsequent amnesia. In two of these four episodes patient developed secondarily generalized tonic-clonic seizures. She was managed in another hospital with carbamazepine $200 \mathrm{mg}$ TID and prednisone $20 \mathrm{mg}$ every $24 \mathrm{~h}$. During the neurological exploration, we found bitemporal hemianopsia in the confrontation campimetry and discrete left hemiparesis $4(+) / 5$. No further cranial nerve, motor, or sensory deficits were identified.

Gadolinium-enhanced magnetic resonance showed an extra axial lesion on the right sphenoid wing $(42 \times$ $42 \times 38 \mathrm{~mm}$ ) and other lesion without continuity of the tuberculum sellae $(23 \times 16 \times 12 \mathrm{~mm})$ with homogeneous enhancement in both lesions (Fig. 1). The endocrine evaluation was normal. Electronic campimetry showed affection of the bilateral temporal visual field and right temporal focal epilepsy was confirmed by an electroencephalogram (EEG).

Given the clinical findings, neuroimaging studies, electronic campimetry and EEG, but especially since both lesions originated clinical manifestations, it was decided to perform microsurgical resection of the two lesions. A Yasargil's incision was made on the right side, with interfacial dissection of the frontotemporal branch of the facial nerve. The temporal muscle was disinserted and a pterional craniotomy was performed. When the bone flap was removed, the middle meningeal artery was coagulated in the foramen spinosum, with the intention of decrease the vascularity to the tumor. After dural opening, the first extra axial lesion became evident and perimetric bipolar dissection of capsule was made. Subsequently proceeded to a central debulking with ultrasonic aspirator and careful hemostasis, a dural attachment was identified in the floor of the middle cranial fossa. When the sphenoid wing lesion was completely resected, a fine dissection was performed using the transsylvian anatomic corridor, reaching tuberculum sellae lesion which compressed the optic nerves. Cytoreduction was performed with an ultrasonic aspirator in the InterOptic and optocarotid spaces, posteriorly the dural attachment was coagulated (Fig. 2). Gadolinium-enhanced magnetic resonance was performed 3 months after the surgery obtaining gross total resection (Fig. 3).

\section{Discussion}

Anterior cranial fossa meningiomas are a heterogeneous group of neoplasms that may involve the crista Galli, olfactory groove, sphenoid plane, tuberculum sellae, clinoid process, and parasellar region. 

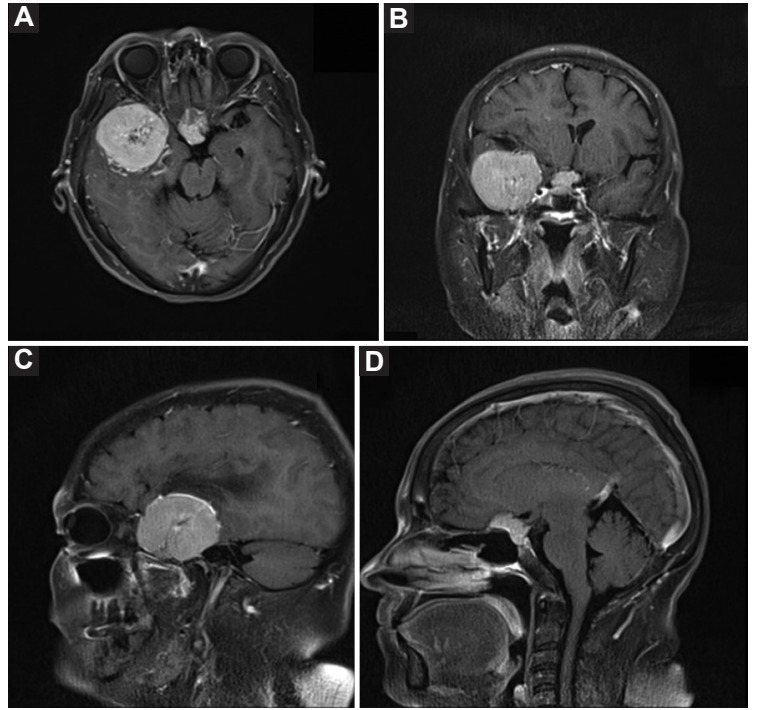

Figure 1. Pre-operative enhanced magnetic resonance imaging of the brain in A, axial section, shows a right sphenoid wing, and tuberculum sellae extra-axial lesions. B, coronal section, right middle fossa lesion with significant compression to temporal lobe, and a lesion in tuberculum sellae. C, parasagittal section shows extra-axial lesion with arachnoid plane and peritumoral edema. D, Sagittal section confirming lesion in the tuberculum sellae with involvement of the optic nerves.
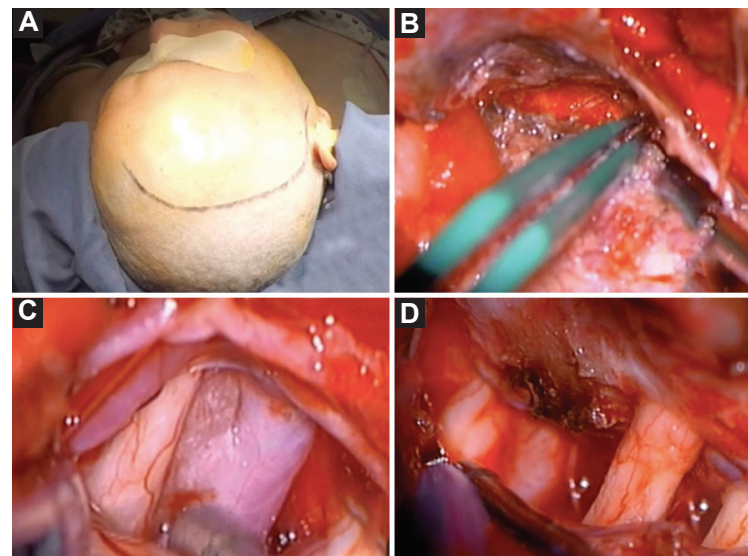

Figure 2. A shows the surgical position and incision. B resection of the right middle fossa meningioma. $\mathbf{C}$ shows the tumor component in the right optocarotid space. D Complete resection in the InterOptic space.

According to dural attachment, sphenoid wing meningiomas are classified into clinoid or internal third, alar or middle third, and pterional or external third.

The term meningiomatosis was first described by Cushing and Eisenhardt in $1922^{12}$. In this report, we present the case of a patient with two meningiomas, the first in the tuberculum sellae, and the second in the middle third of the sphenoid wing, both generated clinical manifestations. Tuberculum sellae meningioma caused bitemporal hemianopsia whilst sphenoid wing triggered epilepsy of the temporal lobe and discrete left paresis. When analyzing the case, it was appreciated that there was no continuity between the tumors, granting diagnosis of meningiomatosis, without association to neurofibromatosis according to known criteria ${ }^{13}$.

The fact of presenting two lesions in different location and with different clinical manifestations, leave us to propose surgical treatment for both tumors. Endoscopic resection is an option for tumors of the anterior cranial fossa, even with the known risks of cerebrospinal fluid fistula, which is reported in some series up to $40 \%$ of cases $^{14}$. Since the size of the sphenoid wing tumor was considerably large, added to the possibility of the resection of the two lesions in a single time with a clear view of the optic nerves, we decided microsurgical cranial approach, which provided safe and excellent treatment, minimizing risks such as cerebrospinal fluid fistula and reintervention.

It is also known that radiosurgery is considered a treatment strategy for meningiomas of the skull base < $3 \mathrm{~cm}$ in diameter and as in the sellar region tumor there must be a distance of at least 3-5 $\mathrm{mm}$ with the chiasm and the optic nerves ${ }^{15}$. In the present case none of the tumors meet criteria for radiosurgery treatment since the sphenoid wing diameter was $>5 \mathrm{~cm}$ and that of the tuberculum sellae displaced the chiasm superiorly.

After the resection of the largest tumor by an anterolateral craniotomy, it gave us the ease of create the corridor through the anterior transsylvian route and to have an adequate visualization of tuberculum sellae lesion. When a careful hemostasis is performed, with a total bleeding of $<600 \mathrm{ml}$ during the first meningioma, resection of a second tumor could be performed.

In our case, in the follow-up the patient had improvement in the visual acuity and in the epilepsy symptoms with an Engel stage 1A. Histopathology analysis reports both WHO Grade 1 transitional meningioma tumors, this improves the prognosis, with an expected 5 -year recurrence rate of $<9 \%{ }^{15}$. The fact that in our case both meningiomas have same histological lineage could support the theory of the spread through cerebrospinal fluid.

According to a literature, we agree that in the case of multiples meningiomas, symptomatic tumor should be treated, while for others surveillance or even radiosurgery is indicated (if the tumor's dimensions allow it). In our case, the two meningiomas were symptomatic, so we decided to manage both in a 

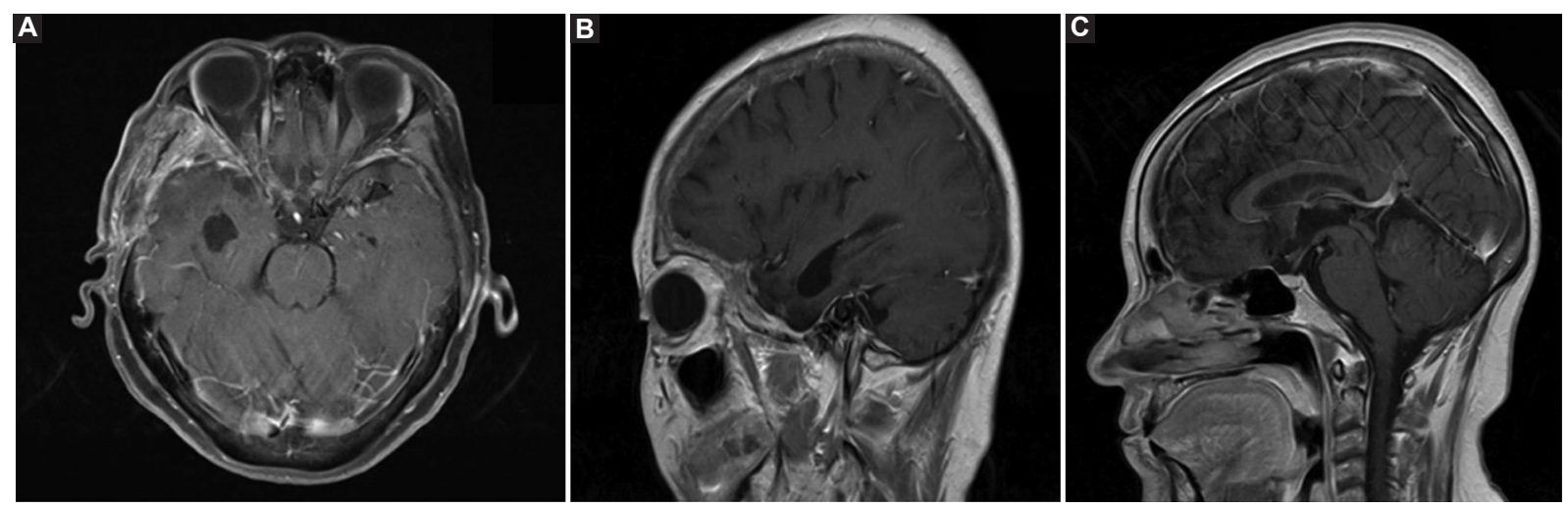

Figure 3. Post-operative enhanced magnetic resonance imaging of the brain. A: axial section showing the post-surgical changes, without evidence of contrast enhancement. B: parasagittal section, shows no residual lesion and no peritumoral edema. C: sagittal section in the sellar region shows preserved pituitary gland, without evidence of compromise to the optic nerves.

single surgical time. Regardless this statement, we recommend trying resection of many lesions as possible if they are close, even, if any of them is not symptomatic.

In contradistinction to the vascular paradigm, where the clipping of multiple aneurysms by means of a single craniotomy, even if not symptomatic is widely accepted by many articles, we did not found literature regarding resection of $\mathrm{MM}$ by means of a single craniotomy, despite this surprising find, we assume that it has been surely performed in many other centers.

\section{Conclusion}

Meningiomas are the most frequent intracranial extra-axial tumors; their various locations provide different clinical manifestations. The diagnosis of meningiomatosis is infrequent and should have a careful study to provide successful treatment for each patient, aiming gross total resection and limiting the damage as much as possible, improving, or preserving patient functional status. The best treatment decision will be the one that provides the best results regarding to the experience of the neurosurgeon.

\section{Conflicts of interest}

The authors declare no conflicts of interest.

\section{Ethical disclosures}

Protection of human and animal subjects. The authors declare that no experiments were performed on humans or animals for this study.
Confidentiality of data. The authors declare that they have followed the protocols of their work center on the publication of patient data.

Right to privacy and informed consent. The authors have obtained the written informed consent of the patients or subjects mentioned in the article. The corresponding author is in possession of this document.

\section{References}

1. Dolecek TA, Propp JM, Stroup NE, Kruchko C. CBTRUS statistical report: primary brain and central nervous system tumors diagnosed in the United States in 2005-2009. Neurooncology. 2012;14 Suppl 5:v1-49.

2. Wong R, Wong A, Vick N, Farhat $\mathrm{H}$. Natural history of multiple meningiomas. Surg Neurol Int. 2013;4:71.

3. Butti G, Assietti R, Casalone R, Paoletti P. Multiple meningiomas: a clinical, surgical, and cytogenetic analysis. Surg Neurol. 1989;31:255-60.

4. Neuss M, Westphal M, Hänsel M, Herrmann HD. Clinical and laboratory findings in patients with multiple meningiomas. $\mathrm{Br} \mathrm{J}$ Neurosurg. 1988;2:249-56.

5. Cahan WG, Woodard HQ, Higinbotham NL, Stewart FW, Coley BL. Sarcoma arising in irradiated bone: report of eleven cases. Cancer. 1998;82:8-34.

6. Sadamori N, Shibata S, Mine M, Miyazaki H, Miyake H, Kurihara M, et al. Incidence of intracranial meningiomas in Nagasaki atomic-bomb survivors. Int J Cancer. 1996;67:318-22.

7. Shibata S, Sadamori N, Mine M, Sekine I. Intracranial meningiomas among Nagasaki atomic-bomb survivors. Lancet. 1994;344:1770.

8. Yonehara S, Brenner AV, Kishikawa M, Inskip PD, Preston DL, Ron E, et al. Clinical and epidemiologic characteristics of first primary tumors of the central nervous system and related organs among atomic-bomb survivors in Hiroshima and Nagasaki, 1958-1995. Cancer. 2004;101:1644-54.

9. Preston DL, Ron E, Yonehara S, Kobuke T, Fujii H, Kishikawa M, et al. Tumors of the nervous system and pituitary gland associated with atomic-bomb radiation exposure. J Natl Cancer Inst. 2002;94:1555-63.

10. Simpson $D$. The recurrence of intracranial meningiomas after surgical treatment. J Neurol Neurosurg Psychiatry. 1957;20:22-39.

11. Jääskeläinen J. Seemingly complete removal of histologically benign intra cranial meningioma: late recurrence rate and factors predicting recurrence in 657patients. A multivariate analysis. Surg Neurol. 1986;26:461-9.

12. Cushing $\mathrm{H}$, Eisenhardt L. Meningiomas: their Classification, Regional Behaviour, Life History and Surgical Results. Springfield, IL: Charles C Thomas; 1938.

13. Shen Y, Nunes F, Stemmer-Rachamimov A, James M, Mohapatra G, Plotkin S, et al. Genomic profiling distinguishes familial multiple and sporadic multiple meningiomas. BMC Med Genomics. 2009;2:42.

14. De Divitiis E, Cavallo LM, Cappabianca P, Esposito F. Extended endoscopic endonasal transsphenoidal approach for the removal of suprasellar tumors: Part 2. Neurosurgery. 2007;60:46-59.

15. Santacroce A, Walier M, Régis J, Liščák R, Motti E, Lindquist $C$, et al. Long-term tumor control of benign intracranial meningiomas after radiosurgery in a series of 4565 patients. Neurosurgery. 2012;70:32-9. 